\title{
Analyzing Students’ Difficulty Based on Revised Bloom's Taxonomy
}

\author{
Rosana Dian Edy Prismana \\ Postgraduate School of Mathematics \\ Education \\ Sebelas Maret University \\ Jl.Ir.Sutami 36A, Kentingan, Surakarta \\ 57126, Indonesia \\ rosanadianedyprismana@yahoo.co.id
}

\author{
Tri Atmojo Kusmayadi \\ Postgraduate School of Mathematics \\ Education \\ Sebelas Maret University \\ Jl.Ir.Sutami 36A, Kentingan, Surakarta \\ 57126, Indonesia
}

\author{
Ikrar Pramudya \\ Postgraduate School of Mathematics \\ Education \\ Sebelas Maret University \\ Jl.Ir.Sutami 36A, Kentingan, Surakarta \\ 57126, Indonesia
}

\begin{abstract}
This research aims to analyze the layout of students' difficulty based on Bloom's Taxonomy revised in terms of low selfefficacy. Revised Bloom's Taxonomy changes the stage knowledge into its own dimension. Owing to the fact that each category on the Taxonomy needs the knowledge as what the students are supposed to be learnt by the students. The revised Bloom's taxonomy has two dimensions, namely the knowledge dimension and the dimension of cognitive processes. On the knowledge dimension, it will be restricted to the conceptual knowledge only. So that, there are 6layout stages of the difficulties which will be analyzed by the researcher in order to find out the site of the student's difficulties in resolving the question of problem solving. The stage layout difficulties which are analyzed are considering conceptual knowledge, understanding conceptual knowledge, applying conceptual knowledge, analyzing conceptual knowledge, evaluating and creating conceptual knowledge. Self-efficacy is a self-belief as someone's belief to achieve the purpose in finishing the given tasks, so it can be seen to what extent the site of the difficulty. Therefore, this research is descriptive qualitative research with qualitative approach. This research is taken 2 students on SE with a low category. From this research, it has obtained the results which students with low SE do not experience all the difficulties at any stage of revised Bloom's Taxonomy. However, there are many factors which make the students encounter errors in resolving the problem solving question. These factors can be the teachers' attention in learning process.
\end{abstract}

Keywords-Bloom's Taxonomy, Self-Efficacy, Students' difficulties.

\section{INTRODUCTION}

In this developed era, it rises up enhancement and development in the quality of learning in every level of education. It is useful to prepare the students to have the ability to think logically, systematically, critically, and creatively. Besides, these capabilities can be developed by the students in learning math because math has the structure and strong and clear linkages between its concepts, so it might be able to create the students' rational thought [8].

In addition, math is a science the abstract patterns which is characterized as a tool to solve the problem as the foundation for the research science and technology [10]. In fact, most of the students have the difficulties in learning math. The students have different perceptions in the math study. Math seems as the most difficult science field [1]. The questions will be the problem if someone does not have the rules which are immediately used to find out the answers based on the questions. That way, a teacher is hoped to optimize the students in understanding the concept and resolving the problems of math through thinking critically, logically, systematically, and structurally. Solving math problems is able to help the students to avoid from the difficulties and apply their ability in any kind of situation [5].

Moreover, it can be seen from the results of national test (UN) of Junior High School Sleman Regency, Yogyakarta in academic year 2013/2014 on mastering math material especially in the math questions. Based on the national examination (UN) absorbance, it seems that the students' mastery of math questions is still low. The ability tested to the students does not meet the minimum final of criterion score (KKM) from the school. There are 24 indicators which are still low based on KKM standard from 40 indicators mastery of math material examined. Also, this case shows that the students of Junior High School (SMP) still face the difficulty in finishing national examination questions on certain math competence. For example, in finishing the problem related to the form of algebra factor, there are $64,57 \%$ students who are able to answer the questions correctly. Finishing the problem related to the function, there are only $53.18 \%$ students who can answer the questions correctly. To solve the problem using Theorem Pythagoras, only 58, 95\% students are able to work on the questions well. The students' goal who are less optimal of achieving the learning result might be because of the students' difficulty in learning process. Hence, the students who face the difficulty tend to have the difficulty in solving the problem either in the class or the students' problem life.

The students' belief to learn the materials which are learnt is considered to be able to influence the students' learning achievement. The students' belief is called as self-efficacy. SelfEfficacy results the differences on how the people think, act, and feel [2][7]. The students' low self-efficacy on math material is caused by most giving up students when they get the 
assignments or math questions which are difficult as what they think. In learning math, the learning concept corncerns on what the students know (knowledge) dan how they think (cognitive). Meanhwile, this case is similar with given concept on the Bloom's Taxonomy which has been revised which divides the dimension intoknowledge dimension and the dimension of cognitive process.

Based on the explanation mentioned before, it can be concluded that the aim of this research is to analyze the students' difficulty and the factor which can cause on solving the problem on math regarding the revised Bloom's Taxonomy.

\section{THEORETICAL BACKGROUND}

In this research, it discusses Self-Efficacy and Bloom's Taxonomy which has been revised.

A. Self-Efficacy (SE)

Self-efficacy is the belief of a person's ability to do something, and it is not as same as knowing what to do [5]. Self-efficacy influences closely on the achievements of students' learning [11][5]. Self-efficacy is the belief that one's about a perceived ability to prepare and finalize the action that is needed to set up a situation that will come [3].

Additionally, in this research, self-efficacy for the students about math is the students' belief on the ability to complete their tasks in order to reach the learning achievement facing math and feeling confident to do their work. Besides, the indicators of self-efficacy which is viewed consist of 3 dimension stages namely level, generality, and strength [4]. On this level, it is related to the degree of the difficulty faced. The acceptance and the belief of someone about the tasks are different. From the statement mentioned, it might that the people only consider on the simple, medium, and difficult task. Every individual's perception will have different views on the level of the difficult tasks.

Generality is the extent to which the individual believes people's ability in a variety of tasks, ranging from the situation in doing a regular activity performed or specific situations that has never been done to a series of task or difficult and varied. The generality is feeling the ability shown through behavior, cognitive, or affective. Strength is the strength of someone's beliefs regarding the capabilities. Individuals who have strong beliefs and steadiness against their ability to work on the task will continue to persist in their own efforts despite having many difficulties and challenges. Weak experience would undermine individuals' belief.

\section{B. Revised Bloom's Taxonomy}

Revised Bloom's Taxonomy includes 2 dimensions on analyzing students' difficulty toward solving problem which is cognitive dimension and knowledge dimension [6]. Knowledge dimension is divided into 4 kinds of knowledge namely factual knowledge, conceptual knowledge, procedural knowledge, and metacognitive knowledge. Conceptual knowledge is static knowledge of the fact and valid concept and principle of certain domain [12]. In knowledge dimension, the students' difficulty is limited on conceptual knowledge.

Cognitive dimension process consists of 6 cognitive processes, and those are remembering, understanding, applying, analyzing, evaluating, and creating [6]. Remembering category is to take relevant knowledge from short-term memory which is needed from someone's long-term memory. Understanding category is connected to the interpreting process. Interpreting process occurs on the students' if the students can change the information from one form presentation to other form presentations. Applying category is defined as the category from cognitive category which includes procedure use or certain job ways to do the exercise or to solve the problem. Analyzing the category is an effort to define the materials into compiling parts and determining the relation among those parts through whole materials. Evaluating category is interpreted as assessment of action making based on the criterion or certain standard. Besides, evaluating category is connected to the checking process. Checking is the process of examining on the internal consistency or internal problem which happens on the operation or production. Creating category is defined as collected certain number of element processes to be coherent and functional unit [6].

TABLE I. KINDS OF STUDENTS’ DifFICULTY BASED ON REVISED BLOOM’S TAXONOMY

\begin{tabular}{|c|c|}
\hline Cognitive Process & $\begin{array}{c}\text { Conceptual Knowledge } \\
\text { Dimension }\end{array}$ \\
\hline Remembering & Remembering concept \\
\hline Understanding & Understanding concept \\
\hline Applying & Applying concept \\
\hline Analyzing & Analyzing concept \\
\hline Evaluating & Evaluating concept \\
\hline Creating & Creating concept \\
\hline
\end{tabular}

\section{RESEARCH METHODOLOGY}

This research is a qualitative research. This research is conducted in Surakarta. The populations of this research are the third junior high school students in Surakarta. The purposive sampling is used to take the data by choosing one subject from one subject category which has been determined, and the subject is a person who has low self-efficacy. There are 3 subjects of this research taken by low self-efficacy category to analyze the difficulty based on revised Bloom's Taxonomy.

The first research step is to give the self-efficacy questionnaires to the students. The second research step is to give the test to the students on how they solve the problem in math concept. The solved questions of the problem are given in a form of explanation question based on the indicator of revised Bloom's Taxonomy. The questions used to analyze the students' difficulty is based on revised Bloom's Taxonomy as following explanation.

Question 1

Known the similarity system as follow: 
$\left\{\begin{array}{c}5^{2} p-9^{\frac{1}{2}} q=2.6^{2}-31 \\ 3^{2} p+10^{2} q=2.10^{2}+118\end{array}\right.$

It includes $\mathrm{P}$ and $\mathrm{Q}$ value required the linear similarity system above. Is the similarity related to the linear similarity in two variables? Please tell the reason. Question number 1 is a question used to analyze whether the students have the difficulty on conceptual remembering based on revised Bloom's Taxonomy. Remembering conceptually is that the students are able to obtain the knowledge from long-term memory regarding the relation among the use of elements together.

Question 2

Given two triangles are $\triangle \odot B C$ and $\triangle P Q R$. Known $\triangle A B C$ has the similar corner as follow; $\angle A=2 y, \angle B=3 x+4 y$, dan $\angle C=x+2 y$. On $\triangle P Q R$ has the similar corner such as $\angle P=$ $3 x-y, \angle Q=2 x+3 y$, dan $\quad \angle R=x+y$.

a. Based on the information existed on $\triangle A B C$ and $\triangle P Q R$, please make the similarity related to the information above?

b. Please determine $\mathrm{x}$ and $\mathrm{y}$ value which can fulfill the similarity of the triangle above?

The question number 2 is a question used to analyze whether the students have the difficulty to understand conceptually on point a and to apply conceptually on pint $b$ based on revised Bloom's Taxonomy. Understanding conceptually is to construct the meaning form of learning materials related to the relation elements which can be used together. Applying conceptually uses the procedure related to the elements together.

Question 3

Reserved 3 large one corner on a triangle is 20 . The large angle of both corners is 3 times bigger than the third great corner. How large is the third corner on its triangle?

Question number 3 is reserved which are used to analyze whether the students have difficulties at the stage of analyzing the layout of conceptually based on the revised Bloom's Taxonomy. Analyzing conceptually it means resolving the matter which is resolved into parts and determined the relationship between the related part of the relationships among the elements used simultaneously.

Question 4

Known the number of two integers of positive is 55 and the quarrel two integers of positive are 25. Look for both the integers of positive by using the method that is most convenient, according to you? Please specify the reason why do you use that method?

Question number 4 is reserved which are used to analyze whether the students have difficulty evaluating the layout of conceptually based on the revised Bloom's Taxonomy. Evaluating conceptually, it means taking decisions based on criteria or standards related relationships among the elements that can be used simultaneously.

Question 5

After a representative of the group determines the bus Agency to rent a bus, now they weigh a package price for the cost of lodging and entrance ticket to the museum. The second package is shown as below. For example, there is a quote from the tour study tour agents offering the package for other costs of hotels and tourist attractions.

For the package A, 3 nights lodging accommodations and attractions 2 tickets are 415000 USD,-per person.

For the package B. 4 nights lodging accommodations and attractions 4 tickets are 620000 USD,-per person. Create an issue that can be solved by using systems of linear equations two variables and solve the problems that you have created.

Question number 5 is reserved which is used to analyze whether the students have difficulty at the stage layout created conceptually based on the revised Bloom's Taxonomy. Creating conceptually, it means combining parts to form something new and coherent relationships between related elements which can be used together.

The next step is doing the third stage in the research, namely the depth interview in against the subject that has been selected based on the first stage and the second stage. The data retrieved is the location of the trouble students with low selfefficacy. The steps of analyzing data are carried out by stages: first collect data by: (1) examining the results of the now selfefficacy of students against mathematics. (2) Categorizing the now self-efficacy on the criteria of high, medium, low, and then choose the students who have self-efficacy with lower categories to be made the subject of research. (3) Checking the test results of students ' mathematical problem solving (correct, true but less complete, there are mistakes, not finished, and not doing).

The second step is to analyze deeper about the layout of the students' problem with determining the factors that affect the students' difficulty based on the layout of overall difficulties found in troubleshooting test results. For the third step, it is the withdrawal of the summary. This stage is taken based on the results of the recent necessary, troubleshooting, and test the results of the interview include: (1) the location of the trouble students in resolving the question of mathematical problemsolving tests, on students who have self-efficacy low (2) summing up the factors of the students ' difficulties in solving math problems which are given.

\section{RESUlT AND DISCUSSION}

This research is conducted on information gathering against a subject to be taken through the self-efficacy. Students categorize on the self-efficacy with the categories of high, medium, low and using the PAN scale 4. Self-efficacy consists of 28 rounds reserved every grain has a range of 0 to 5 .

Taken 3 subjects on the subject with low criteria for difficulty in working on the problem-solving of math test. The results of the test analysis tests in math problem solving of the students can be seen in the following description.

A. The answer number 1

1). Subject $A$

Yes.

The reason: the similar linear consists of 2 variables.

2). Subject B

Yes.

The reason: it includes two variables of similarity of linear system which consist of its adding and decreasing. 
3). Subject $C$

Yes.

The reason: the similarity only includes 2 variables $p$ and q.

The explanation:

The analysis result based on the answer test to solve math problem and citation of interview guidelines.

Subject A answers correctly with uncompleted answer, subject $\mathrm{B}$ has the mistake in answering the questions, and subject $\mathrm{C}$ answers the question correctly but still having uncompleted answer.

Interview guidelines;

Researcher : Do you face the difficulty in doing question number 1 ?

The subject's response

Subject A said that "I do not have any difficulty". Subject B said "No". Subject C answered "No".

Researcher : What is the requirement of the similarity called as

Subject's response: SPLDV?

Subject A said that "has two different variables". Subject B said "it has two variables such as $p$ and $q$ in the question". Subject C said that "there two variables on two different similarities".

Seeing from the results of the third subject answers that most of the answers are correct but less complete and the results of excerpts' interview stated that all three questions do not have difficulty based on doing the problem. It means that the subject with low SE do not have difficulty in working on the problem with remembering conceptually. The students' answers are less complete, in-depth interviews when conducted after apparently derived from a factor of the materials. When giving to teach about SPLDV, the teachers just give the sense that the SPLDV attribute has a variable as much as 2. Two similarities become SPLDV because two similarities have fulfilled two similarities.

B. The answer of question number 2

1). Subject $A$

a. $\angle A+\angle B+\angle C=360^{\circ}$

$2 y+3 x+4 y+x+2 y=360^{\circ}$

$x+2 y=90^{\circ}$

$\angle P+\angle Q+\angle R=360^{\circ}$

$3 x-y+2 x+3 y+x+y=360^{\circ}$

$2 x+y=120^{\circ}$

b. $x+2 y=90^{\circ}$

$x=90-2 y$

$2 x+y=120^{0}$

$2\left(45^{0}-2 y\right)+y=120^{0}$

$90^{\circ}-4 y+y=120^{\circ}$

$-3 y=30^{\circ}$

$y=-10^{0}$ (Impossible)

In fact, $x=45^{0}-2 y$

2). Subject $B$

$x=45^{0}+20^{0}=65^{0}$

$$
\begin{aligned}
& 3 x-y+2 x+3 y+x+y=180^{\circ} \\
& 6 x+4 y=180^{\circ} \\
& 3 x+2 y=90^{\circ} \\
& \text { In } \triangle P Q R \\
& \angle P+\angle Q+\angle R=180^{\circ} \\
& 3 x-y+2 x+3 y+x+y=180^{\circ} \\
& 6 x+3 y=180^{\circ} \\
& 2 x+y=60^{\circ} \\
& 3 x+2 y=90^{0} \quad \mathrm{x} 1 \quad 3 x+2 y=90^{0} \\
& 2 x+y=60^{0} \quad \mathrm{x} 2 \quad 6 x+2 y=120^{0} \\
& \begin{aligned}
y & =60^{0}-2\left(10^{0}\right) \\
& =40^{\circ}
\end{aligned}
\end{aligned}
$$$$
-3 x=-30^{0}
$$$$
x=10^{0}
$$

The explanation:

The analysis result based on the test answer of math problem and interview quotes.

The answer of subject $A$ and subject $B$ has the mistake. The subject $C$ does not finish yet in answering the questions. The interview guidelines:
Researcher :
Do you have the problem doing your question number 2 ?

Subject A said "I finish the test, and I do not have any difficulty". Subject B said "I do not have any difficulty". Subject $\mathrm{C}$ said that" I just answer the question number 2, and I have not finished them yet, but for me, the question number 2 is not difficult".

Three subjects do not have any difficulty in understanding the test conceptually and applying conceptually. In fact, the answer given by three subjects are wrong.

On the subject $\mathrm{A}$, he/she has the mistakes in understanding the amount of angle in the triangle is $180^{\circ}$ rendered $360^{\circ}$. Subject $\mathrm{B}$ encounter errors in the calculation due to the less meticulous. Subject $C$ cannot set his/her own time to work on it, so that the answers are less complete or not complete.

C. The answer of question number 3

1). Subject $A$

$\angle A+\angle B+\angle C=360^{\circ}$

$23^{0}-360^{\circ}=$ The third corner

The third corner $=157^{0}$

2). Subject $B$

The third corner is $180^{\circ}-100^{\circ}=80^{\circ}$ 
1). Subject $A$

In package $\mathrm{A}$, the lodging accommodation for 3 nights and two tourist tickets is $R p 415000,-$ per person.

Explanation:

$$
180^{\circ}-20^{\circ}=160^{\circ}
$$$$
\text { The third subject is } \frac{160^{\circ}}{3}=53^{0}
$$

The results of the analysis based on mathematical problem solving test answers and excerpts of the interview are mentioned as follow. The subject of A, B, and C have the error answers. Absolutely, it is clear that the third subject does not have a logical answer

The interview conversation:

Researcher : Do you have the difficulty to answer question number 3 ?

Subject A, "yeah, I get difficulty in making math model". Subject B said "I am a bit confused to find out those triangle corners". Subject C, "I have answered the question whether it is correct or not".

From the results of the analysis tests and interviews, most of the Subjects have difficulty on questions with conceptual analyzing phase. The difficulty of the subject is because the subject cannot interpret a mathematical statement into a mathematical model.

D. The answer of question number 4

$$
\begin{aligned}
& \text { 1). Subject } A \\
& a-55 \\
& a+25 \\
& a=30 \\
& b=\frac{30}{2}=15
\end{aligned}
$$

\section{2). Subject B}

Numeral integers of positive = $27,28,30,32,34,35,36,38,40,42,44,45,50$.

It is easy to use that method.

\section{3). Subject C}

$$
x-y=25
$$

Explanation:

The analysis results are based on the answer test in solving the problem of math and the quotation of the interview. Subject A and Subject B have the incorrect answers. Subject C has uncompleted answer or not finished yet.

The interview:

\section{Researcher : Do have any difficulty to} answer question number 4 ?

Subject A feels "difficult". Subject B said "I have the difficulty". Subject C has "the difficulty".

Most of the subjects have difficulty in answering question number 4. Also, the subjects feel difficulty in evaluation step conceptually.

The subject has the difficulty because of some factors that can be observed in accordance with the answers and the results in the interview which has less thorough to read the questions. Then, the difficulty is interpreted the question into a mathematical model.

E. The answer of question number 5
In package $\mathrm{B}$, the lodging accommodation for 4 nights and two tourist tickets is around $R p 620000,-$ per person.

2). Subject $B$

-

3). Subject $C$

Package A $=415000$

Package $\mathrm{B}=620000$

The question: how much is the price of the package $\mathrm{A}$ and $\mathrm{B}$ if it includes 4 people to stay?

Package $A=415000 \times 4=1660000$

Package $B=620000 \times 4=2480000$

The explanation:

The results of the analysis based on the answer to a third subject experiences the errors in doing the tests.

The interview quotation:

Researcher : Do you have the difficulty to answer question number 5 ?

Those three subjects answer "difficult".

This means that most of the Subjects have difficulty in creating conceptual stage. Subject A just writes down the known only in accordance with the problem. This means Subjects have difficulty to write down the answers, and they just answer the question based on what they know only. Subject B does not answer question number 5. This means Subjects B really can't answer it. Subject $C$ can write commands that might be on question number 5. This means Subjects $C$ is able to create an issue that appears on question number 5 , but the arguments being made does not correspond to the concept of SPLDV. It means that the subject $C$ is not too familiar with the concept at SPLDV.

On the research which has been done, most of junior high school students have the difficulty in answering the essay question (story question) which is in factual knowledge (38,4\%); conceptual knowledge $(75,4 \%)$; procedural knowledge (98,8\%); and metacognitive knowledge (100\%). Kinds of the difficulty faced by the students are mentioned in remembering the fact $(31,9 \%)$; remembering the concept $(47,9 \%)$; understanding the fact $(18,9 \%)$; understanding the concept (66,5\%); applying the concept(72,6\%); applying the procedure $(72,6 \%)$ analyzing the procedure $(96,7 \%)$; evaluating the fact $(30,7 \%)$; evaluating the concept $(70,7 \%)$; evaluating $(98,8 \%)$; and communicating metacognitive (100\%) [9].

\section{CONCLUSION}

Based on the information obtained of the research, it can be concluded that the students who have low SE will not have the difficulty to remember conceptually. However, the material factors given by the teacher becomes the students' main answer. the students with low SE do not face the difficulty in understanding the steps conceptually and in applying math problem solving tests and guidelines for interviews. The 
conceptually. Besides, the factors can come from less paying attention in counting algebra, and it can be caused the basic concept about the information related lack of math mastery. the students who has low SE have the difficulty in analyzing conceptually, evaluating conceptually, and creating conceptually. The students' difficulty is caused the students who cannot interpret the statement of the question in math model. This case is usually caused of students' less exercising to answer the math questions which are interpreted to be math module.

\section{RECOMMENDATION:}

For the teachers, the researcher hopes to understand into kinds of difficulty faced by the students when they learn math especially for the students who have low SE. the teachers are hoped that they can understand the kind of factors which can the cause of the students' difficulty in learning math. For other researchers, The researcher hopes that other researchers can analyze the problems which become the factors for the students' difficulty in answering the math questions. The researcher also hopes this research results can be a reference for the teachers to create teaching and learning process in the class to enhance the students' capability.

\section{ACKNOWLEDGMENT}

The authors thank to the Postgraduate School of Mathematics Education Sebelas Maret University.

\section{REFERENCES}

[1] Abdurrahman, M. Anak berkesulitan belajar: Teori, Diagnosis, dan Remedialnya, Jakarta: Rineka Cipta, 2012.

[2] A. Bandura and N. E. Adam, "Analysis of self efficacy theory of behavioral change", In Cognitive Theory and Research, vol.1, pp 287-310, 1997.

[3] A. Bandura, Self-efficacy in Changing Societies, Cambridge, UK: Cambridge University Press, 2009.
[4] A. Bandura, Self-efficacy: The Exercise of Control, New York, NY: Freeman, 1997.

[5] D, H. Schunk, Learning Theories ( $6^{\text {th }}$ ed $)$, Boston, MA: Pearson Education, Inc, 2012.

[6] L. W. Anderson and D. R. Krathwohl, Kerangka Landasan untuk Pembelajaran, Pengajaran, dan Asesmen: Revisi Taksonomi Bloom, New York, NY: Pearson AddisonWesley, 2010.

[7] M. K. Zarch and P. Kadivar, "The role of mathematics selfefficacy and mathematics ability in the structural model of mathematics performance," Proceedings of the 9th WSEAS International Conference on Applied Mathematics, vol. 9, pp 242-249, 2006.

[8] N. E. Purnaningsih and T. Y. E. Siswono, "Profil metakognisi siswa dalam memecahkan masalah matematika ditinjau berdasarkan tipe kepribadian," Mathedunesa Jurnal Ilmiah Pendidikan Matematika, vol. 3, pp. 152-159, 2004.

[9] N. Novferman, "Analisis kesulitan dan self-efficacy siswa SMP dalam pemecahan masalah matematika berbentuk soal cerita" vol. 3, pp 76-87, 2016.

[10] P. Chambers. Teaching Mathematics: Developing as a Reflective Secondary Teacher. London, UK: Sage Publication, 2008.

[11] S. Hamdi and A. Abad, "Pengaruh motivasi, self-efficacy dan latar belakang pendidikan terhadap prestasi matematika mahasiswa PGSD STKIP-H dan PGMI IAIH," Jurnal Riset Pendidikan Matematika, vol. 1, pp. 77-87, 2014

[doi: http://dx.doi.org/10.21831/jrpm.v1i1.2666].

[12] T. D. Jong and M. G. M. F. Hessler. "Types and qualities og knowledge. Educational Psychologist”, vol. 31, pp. 105113, 1996. 